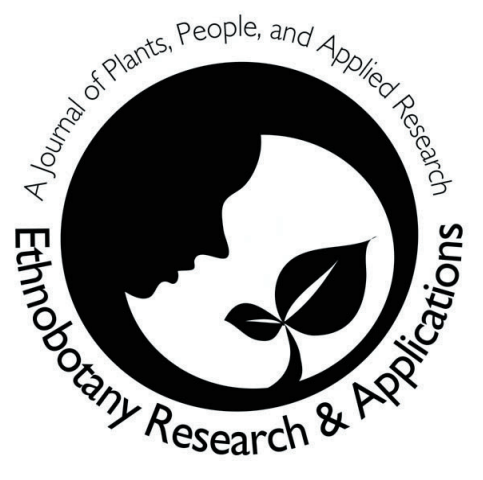

\title{
The Neglected Key to Successful Biodiversity Conservation and Appropriate Development: Local Traditional Knowledge
}

\author{
Nat Quansah
}

\begin{abstract}
The need to conserve the worlds' biodiversity is no longer a controversial issue. However, the question of how to conserve biodiversity is a pressing issue. The evidence of this is seen in the continued loss of biodiversity, especially in the rich biodiversity countries of the world, despite the efforts by many governments and non-governmental organizations and individuals. Similarly, the need for countries to develop is not an issue but which types of development and how development is implemented are important issues. So how do we arrive at successfully conserving biodiversity and achieve appropriate development programs? This paper presents local traditional knowledge as the neglected key to successful biodiversity conservation as well as appropriate development programs. Successful biodiversity conservation and the implementation of appropriate development programs, it is suggested, may be ccomplished by consciously targeting and harnessing local traditional knowledge. The effectiveness is based on the various relationships that exist between people of diverse cultures and the other elements of biodiversity in their respective areas.
\end{abstract}

\section{Introduction}

The World's biodiversity is being lost at a rate unprecedented in the annals of history as a result of mass habitat loss (Hamann 1991). The conservation of these rapidly diminishing natural habitats has become a global priority.

Different approaches have been (and are being) tried to find ways to minimize and/or stop the loss of biodiversity, especially in the biologically rich areas on Earth. The different approaches have not consciously targeted and harnessed local communities' links with biodiversity (knowledge of and dependence on biodiversity) as a positive tool to help arrive at conserving local biological and cultural (biocultural) diversity while improving the well-being of these communities at the same time. This is because most of the approaches have been founded on the erroneous concept that has regarded people (especially local people) as a menace to biodiversity and have attempted to 'save biodiversity' by excluding these people.

The establishment of a network of protected areas where human activities (especially that of local communities) are strictly forbidden (or minimally allowed) is regarded as essential for conserving natural habitats. This is evidenced by the increase in the number of protected areas around that exclude or minimise human activities. In Africa, for example, the number of protected areas has increased significantly since the 1960 s to at least 698 sites totaling more than 134 million hectares. Of these protected area sites in Africa, $67 \%$ do not allow extraction of wild resources by local communities (World Conservation Monitoring Centre 1992). This is in spite of the clear evidence of the strong dependence on wild resources (biodiversity) by people, especially, rural communities and the fact that some of the resources required by these people only occur in the designated protected areas (Makombe 1994, Okafor 1989, and personal observations).

\section{Correspondence}

Nat Quansah, Independent Researcher/Consultant, Health \& Environmental Issues, MADAGASCAR. natquansah@hotmail.com

Ethnobotany Research \& Applications 2:89-91 (2004) 


\section{The Principle of Conservation}

What comes to mind when we hear the term "biodiversity conservation"? I believe most of us immediately think of the forests of Africa, Asia, Central and Southern America. We also think of how local people in these areas have destroyed (and are destroying) these forests and the need to help prevent them from doing that.

I don't believe that local people would willfully destroy the resources that they depend on. But, let's say that, yes local people are "destroying" the natural habitats that they and other organisms inhabit. The question is why? Why would people destroy the areas and the resources that have sustained (and continue to sustain) them?

I believe the answer lies to a greater extent in the way researchers, conservationists, developers, and governments have considered and treated local people. When it comes to the development and/or conservation of biodiversity of an area, local communities have often been treated as people with no clues about how to survive in the areas that they've inhabited and continue to inhabit. Their knowledge of their own environment has often been disrespected, belittled and ignored. When the knowledge has been "considered" it has not been in the interest of the providers of the knowledge or their community. Instead, knowledge has been falsely considered as the basis for exploition and abuse of the environment to the detriment of the majority. Local communities have often been led to believe that their own way of life, depending on local biodiversity must be shunned in favor of alternative lifestyles. These alternatives, however, usually alter traditional patterns of interaction with the environment beginning with mismanagement and eventual destruction of local biodiversity and cultural practices.

Conservation as defined within the World Conservation Strategy is: "the management of the human use of the biosphere so that it may yield the greatest sustainable benefit to present generations while maintaining its potential to meet the needs and aspirations of future generations" (IUCN 1980). At the heart of conservation is sustainable use of resources (including biodiversity). That is, using resources in ways that enable the resources to meet the needs and aspirations of the current user without jeopardizing the resources ability to meet the needs and aspirations of future users (Quansah \& Quansah 1995). This contrasts with the strategy of preventing, disallowing and denying the use of biodiversity by people in order to "save biodiversity" adopted by some conservationists and developers. The adoption of this strategy that denies people the use of biodiversity, I believe stems from the misunderstanding of the principle of conservation by those conservationists who have considered conservation strictly as the act of keeping biodiversity from change or loss, by protecting and preserving it. These forget, though, that natural biological systems as well as cultures are dynamic and not static. If these systems are dynamic then we cannot keep them from changing. We must rather work within these systems and help them attain their balances through change.

On other hand, if the principle of conservation has been understood, then actions on the ground have indicated that the principle has been misapplied. If that is the case, then I ask, is this misapplication willful or not? Whatever the response is ground results as regards development and biodiversity conservation programs have not been satisfactory. We deny people access to local resources and encourage them to seek and use alternatives that they usually have no access to and often cannot afford, forgetting that non-accessibility and non-affordability result in non-availability. This has led to inappropriate conservation and development programs resulting in conflicts with local communities with both biological and cultural diversities becoming the victims. It's time to apply the principle of conservation if we really want to succeed.

\section{Links between People and the other Elements of Biodiversity}

There are diverse links between people of all walks of life and the other elements of biodiversity around them. These links manifest themselves in local traditional knowledge of as well as the use to which different people of diverse cultures put biodiversity. The people-biodiversity links are seen in many different areas such as health (medicines, cosmetics), nutrition (food), energy (fuel wood, coal), construction (shelter, utensils, tools), transport, entertainment, religion and cultural identity.

\section{Effects of the People-biodiversity Links}

The survival of humans has depended (and will continue to depend) on the success of the people-biodiversity links (relationships). These relationships known through the different uses of biodiversity enable people to take stock of the need to have continued access to resources thereby making them find ways to maintain and keep the relationships going for as long as practicable.

Various communities have used (still use) diverse strategies that have enabled them to keep the people-biodiversity links active. The strategies include:

- collecting wild plants

- hunting wild animals

- cultivating and breeding certain species of plants and animals

- $\quad$ creating sacred areas where access are restricted

- $\quad$ attributing a tribes existence to a particular species making it an offence to destroy that species

- banning activities (such as hunting, farming and/or fishing) in certain areas for certain periods of time 


\section{N. Quansah - The Neglected Key to Successful Biodiversity Conservation and Appropriate Development: Local Traditional Knowledge}

These strategies have often led to the conservation of biodiversity as well as the culture of an area. Furthermore these strategies have exisited prior to implementation of formal conservation and development programs.

Rather than seeking to understand the mechanisms and details of the strategies employed by local people, we (the educated lot) tend to belittle, ignore and neglect these and suggest procedures and activities that are alien to local people. Futhermore, the procedures proposed are often theoretical/untried and therefore experimental, as opposed to local strategies that have been tried over generations.

Neglecting the people-biodiversity relationship through belittling of local knowledge, beliefs and practices has led to a disconnection of people from their local Nature (biodiversity). When the links of a people with Nature have been severed, it becomes difficult for such people to wake up to the call to take up their responsibilities to care for and work with Nature for their own good (let alone for the good of Nature and others). This eventually results in the loss of culture AND biodiversity. Development programs implemented in such an area are hardly appropriate and will very likely be unsuccessful.

\section{The Way Forward}

Building on existing links between people and biological resources to help meet local aspirations for development, in the context of sustainable use of resources, has of late ben considered a key to help alleviate socio-economic hardships and conserve biological and cultural diversities (Craven 1990, Pimbert \& Pretty 1995, Wells \& Brandon 1992). The level of success of this, however, is dependent on the recognition and accommodation of local community knowledge, interests and priorities and the level of their involvement in the development and conservation initiatives.

\section{Reinforcing Peoples' Links with Nature}

The active USAGE of biodiversity is a fundamental link between people and the environment. We cannot stop people from using biodiversity. That is a fact of life. Conservation and development programs must NOT try to sever the links between people and Nature. These programs must rather reinforce the links by helping meet socio-economic and biocultural diversity conservation needs of the people and their area all at the same time.

Targeting and harnessing local traditional knowledge as manifested in the uses of biodiversity will make people take up their responsibilities to help save biodiversity. Development programs arising from this approach would reinforce local capacities to manage their resources with external resources coming in to complement rather than to replace those already existing locally. In this sort of development program, reinforcment and complemention of local capacities and resources is the focus of what I term appropriate development. Such a development program will not "turn people into beggars", but will empower people to use biodiversity sustainably for themselves and for others.

Yes, the conservation of the rapidly diminishing natural habitats of the world is now a global priority. It is possible to minimize and/or stop this loss if we would only change our attitudes and actions from ignoring, belittling and neglecting local traditional knowledge, a vital key in this quest, to acknowledging the importance of this knowledge.

\section{References Cited}

Craven, I. 1990. Community involvement in management of the Arfak Mountains Nature Reserve. World Wildlife Fund (Indonesia), Jakarta.

Hamann, O. 1991. The Joint IUCN-WWF Plants Conservation Programme and its Interest in Medicinal Plants. Pp 13-22 in Conservation of Medicinal Plants. Edited by Akerele, O., V. Heywood \& H. Synge. WHO, IUCN \& WWF. Cambridge Univ. Press. Cambridge.

IUCN. 1980. World Conservation Strategy. IUCN/WWF/ UNEP. Gland, Switzerland.

Makombe, K. 1994. Editor of Sharing the Land: Wildlife, People and Development in Africa. IUCN/ROSA Environmental Issues Series No. 1, IUCN/ROSA, Harare, Zimbabwe and IUCN/SUWP, Washington, USA.

Okafor, J.C. 1989. Agroforestry Aspects. World Wide Fund for Nature, Surrey, UK.

Pimbert, M.P. \& J.N. Pretty. 1995. Parks, People and Professionals: Putting 'Participation' into Protected Area Management. Discussion Paper No. 57, UNRISD, Geneva.

Quansah, N \& P. Quansah. 1995. Saving biodiversity of extinction: The need to understand and practice the principle of conservation. Hanitriniala 7:19-20.

Wells, M. . \& K. Brandon. 1992. People and Parks Linking Protected Area Management with Local Communities. The World Bank/WWF/USAID, Washington, DC.

World Conservation Monitoring Centre (1992). Global Biodiversity: Status of the Earth's Living Resources. Chapman and Hall, London. 